\title{
THE LAWS OF HISTORICAL PHONETICS DEVELOPMENT IN JAZERY (SEMITIC) LANGUAGES
}

\author{
Dr. Bushra Hussein Ali Alfadhli \\ PhD Arabic Language/Phonetics \\ Ministry of Education -The Istqlal Secondary School for Girls
}

DOI: $10.37648 / \mathrm{ijrssh.v10i02.044}$

Received: 15 ${ }^{\text {th }}$ April, 2020; Accepted: 04 $4^{\text {th }}$ May, 2020; Published: $18^{\text {th }}$ May, 2020

The Language is developing and live and passes through stages of changes until it reach to oldness stage then it dies such as living creatures .Steven Olman said "Language is not still or dead in any case ,although its advance may look sometimes slow" $"$.

The first matter that appears from the laws of language development that work on making changes in is reflected in the sound change, i.e the features of sounds begin to change to another features and that cause to generate a new sounds and die of some existed sounds .

Phonetics development subject was studied by Arab old and modern orientalist and others under various titles such as :replacement, derivation ,bigger derivation , phonetic change, phonetic development ,phonetic exchange or historical phonetic transformation .

The absolute (historical change) is the change that occurs on sounds to transform it to another sound in all their linguistic context to be missed from the phonology of this language .The limited change is a group of changes that occurs in a sound in some language and cause its change to another sound in some of its linguistic context .

The changes that occur in sounds are two groups : constant and agreed which is the irregular the constant

\footnotetext{
${ }^{1}$ The role of word of in language :156
}

is divided into absolute (historical ) and limited (synthetic)

The orientalist (Brajistraser ) represented the absolute change by substitute $\mathrm{Ba}^{\prime}$ by $\mathrm{Fa}^{\prime}$ ( We do not find for this change a phonetic condition that restricted to it, in the restricted their example is that the original Meem in the end of the words becomes Arabic Noon ,that the change of Meem into consonant Noon is occurred in many words from one side and from the other side it was restricted in that it occurs on the ends of these words and does not passed them to the middle and its example is Nunation as its origin is the Mem as in Akkadian and Sabaian such as Baytan, its origin is Baytam ${ }^{2}$.

(Brajistraser) sees that the problems of the articulation has no clear science unless in few case such as that Akkadian has lost all the Pharyngo-Laryngeal letters such as العين و الحاء and the cause of all that is that the first people of Iraq is Summerian, then Semitic people peoples lived in Iraq and mixed with its people so Sumerians toke the Semitic language and as PharyngoLaryngeal letters were not existed in Akkadian language they did not pronounced them in the Semitic languages also and neglect them till they vanish .the problem that impose the change of letters in this situation is the mixture of two languages ${ }^{3}$

\footnotetext{
${ }^{2}$ Grammar Development of the Arabic :27

${ }^{3}$ Grammar Development of the Arabic:27-28
} 
The phenomena of sound transformation is common phenomena in all the world languages such as Semitic and letters change are called Sounds laws ${ }^{1}$.

Examples of Sounds laws is Grimm Law which is study that is called( Sound change ) and it is connected with with direct substitution in voiceless sounds in German language. Grimm explains that German languages when join one of its words $(F)$ that has its similar in common words in Latin, Greece and Sanskrit the letter $(\mathrm{P})$ and in other languages is similar to letter ( $t$ ) and when assimilate the letter that is symbolized by circle includes slash is Voiceless dental fricative $(\boldsymbol{\theta})$ sound similar to Arabic $ث$ and is similar to $(\mathrm{T})$ in other languages and Grimmexpalins this similarity as hypothesis that there is a change in the sound in some period of Germanic history ${ }^{2}$.

There is other law is the law of the strongest means( Where a sound effect in other the weakest sound (in its position in the syllabic or in its articulation extension ) is influenced by the other ${ }^{3}$.

- Law of facilitate and easiness :the language tendes to remove difficult sound and replace them by other sounds that do not need a great muscle effort .The jin some Arabic dialects are replaced by د such as in (دهب) in place of (ذهب) (ذهب (ذكر) or $j$ in jinstead of (ذكر (د) (ذبر ${ }^{4}$.

- Law of Palatal sounds :the sound of end such as 5 and $ج$ or in Cairo $ج$ tend in their articulate to their analogue in front sounds and the comparison of all Semitic languages indicates that the original pronunciation of Arabic ج was without stress such as Cairo $ج$ as the word Camel is gamal in Hebrew, gamla in Aramaic and gamal in Abyssinian ${ }^{5}$.

- Acoustic mistake is historical sound change resulted sound changes such as consequent of ضin Arabic

- Sound closeness in pronunciation and feature : This closness cause the sound exchange between them .

- There are sound changes that do not subject to the above mentioned laws but to linguistic tradition of some area (substrate) the long Fathachange to long Dhamaoccurs in all

\footnotetext{
${ }^{1}$ See The Bases of Linguistics :140,Mario Bay

${ }^{2}$ See ,The Language :170 Findrs

${ }^{3}$ Study of Phonology :319 Ahmed Mukhtar Omar, $1^{\text {st }}$ edition ,Cairo, 1976.

${ }^{4}$ Ipid : 83-84 and see; Introduction to phonology

${ }^{5}$ See :language Development 132.
}

languages that entered Syria and Palestine such as (كاس) in Arabic is (كوس () Kos in Hebrewand king in East Syrianic (in Iraq) is Molko in Western Syrianic ${ }^{6}$.

And the test of the age is another difficulty for the sound change. The example is Arabic language wher some of Cairo people find difficulty in pronounce 3 and replace it by find that in other countries in their dialects such as people of Cairo, Damascus and Jerusalem .
${ }^{6}$ The mistakes of the commons :53, Ramadan Abdultawab and his resource is Spracht las 